\title{
HUBUNGAN ANTARA DUKUNGAN SUAMI DENGAN KECEMASAN SELAMA PERSALINAN PADA PRIMIGRAVIDA DI PUSKESMAS MLATI II SLEMAN
}

\author{
Retnowati ${ }^{1}$, Retno Mawarti ${ }^{2}$, Dwi Yati ${ }^{1}$ \\ ${ }^{1}$ Stikes Jenderal Achmad Yani Yogyakarta \\ Jl. Ringroad Barat, Ambarketawang, Gamping, Sleman, D.I.Yogyakarta \\ ${ }^{2}$ Stikes Aisyiah Yogyakarta
}

\begin{abstract}
Background: Labor is the process of delivering a baby that occurs in full-term pregnancy (37-42 weeks). One of the efforts to reduce anxiety during labor is to provide support from a significant person, a husband. Husban's support in labor process is a source of strength for woman who cannot be replaced by health personnel.

Objective: To identify the relationship between husband's support and anxiety level during labor on primigravida at Mlati II Health Center Sleman.

Methods: This study was descriptive quantitative, with cross sectional approach. The samples were 20 respondents who were selected withaccidental sampling technique. Research employed questionnairesto measure husband's support and mother's anxiety level. Study used univariable and bivariable analysis.

Result: Most of the husband's support during labor on primigravida at Mlati II Health Center Sleman were at high category $(75.0 \%)$. The majority of mothers experienced mild anxiety $(50.0 \%)$. The relationship between husband's support and anxiety during childbirth in primigravida mother at Mlati II Health Center Sleman district was at strong category; $r=-0.632$ (.600 to .799$)$.

Conclusion : There was a relationship between husbands' support andprimigravida mothers' anxiety level
\end{abstract} during labor at Mlati II Health Center Sleman.

\section{PENDAHULUAN}

World Health Organization

memperkirakan di seluruh dunia setiap tahun lebih dari 585 ribu ibu meninggal pada saat hamil dan melahirkan. ${ }^{(1)} \mathrm{Di}$ Indonesia angka kematian ibu dan bayi masih tinggi, berdasarkan hasil Survei Demografi dan Kesehatan Indonesia (SKDI) tahun 2012 didapatkan angka kematian ibu mencapai 359 per 100 ribu kelahiran hidup. Angka tersebut mengalami peningkatan dibanding dengan hasil SKDI tahun 2007 di mana angka kematian ibu hanya 228 per 100 ribu kelahiran hidup ${ }^{(2)}$

Kematian ibu saat persalinan disebabkan oleh beberapa faktor meliputi pendarahan $32 \%$, hipertensi dalam kehamilan $25 \%$, infeksi $5 \%$, abortus $1 \%$, dan partus lama $5 \% .{ }^{(3)}$ Salah satu penyebab kematian ibu disebabkan karena adanya partus lama yaitu sebanyak $5 \%$. Salah satu penyebab partus lama adalah kecemasan saat persalinan.

Persalinan sendiri dapat diartikan sebagai proses pengeluaran yang terjadi pada kehamilan cukup bulan (37-42 minggu), lahir spontan dengan presentasi belakang kepala yang berlangsung dalam waktu 18-24 jam tanpa komplikasi, baik pada ibu maupun pada janin. ${ }^{(4)}$ Selama persalinan ibu mengalami perubahan psikologis dan fisiologis. Salah satu kondisi psikologis yang dapat menghambat proses persalinan adalah kecemasan. ${ }^{(5)}$

Kecemasan merupakan bentuk perasaan khawatir, gelisah, dan perasaan- 
perasaan lain yang kurang menyenangkan dalam menghadapi suatu keadaan. ${ }^{(6)}$ Biasanya perasaan-perasaan ini disertai oleh rasa kurang percaya diri, tidak mampu, merasa rendah diri, dan tidak mampu menghadapi suatu masalah.

Beberapa upaya yang bisa dilakukan untuk menurunkan kecemasan saat persalinan yaitu dengan cara: Asuhan sayang ibu dan sayang bayi dengan prinsip mengikutsertakan suami dan keluarga selama proses persalinan dan kelahiran janin, saling menghargai budaya, kepercayaan, dan keinginan sang ibu. Salah satu upaya yang bisa dilakukan untuk menurunkan kecemasan saat persalinan adalah dengan mengikutsertakan atau adanya dukungan suami selama persalinan.

\section{BAHAN DAN CARA PENELITIAN}

Jenis penelitian ini adalah deskriptif analitik dengan metode kuantitatif, menggunakan rancangan cross sectional, yaitu jenis penelitian yang menekankan pengukuran variabel bebas (independent) dan variabel terikat (dependent) dilakukan dalam waktu yang bersamaan. ${ }^{(7)}$ Untuk mengetahui ada tidaknya "Hubungan Antara Dukungan Suami Dengan Kecemasan Saat Persalinan Pada lbu Primigravida di Puskesmas Mlati II Kabupaten Sleman".

Pengambilan sampel pada penelitian ini menggunakan teknik accidental sampling dengan subjek penelitian 20 responden, instrumen berupa kuesioner yang terdiri atas kuesioner dukungan suami dan kuesioner tingkat kecemasan.

Variabel dalam penelitian ini terdiri atas 3 kelompok variabel yaitu Variabel bebas (independent): dukungan suami, Variabel terikat (dependent): kecemasan saat persalinan, dan variabel pengganggu: usia, nyeri persalinan, tingkat pendidikan, faktor pengalaman (graviditas), pekerjaan, dan budaya. Analisis data yang digunakan yaitu menggunakan uji Spearman Rank Correlation.

\section{HASIL DAN PEMBAHASAN PENELITIAN}

\section{Karakteristik Responden}

Penelitian ini menguji hubungan antara dukungan suami dengan kecemasan saat persalinan pada ibu primigravida di Puskesmas Mlati II Kabupaten Sleman dengan sampel berjumlah 20 istri.

Tabel 1 Karakteristik Responden di Puskesmas Mlati II Kabupaten Sleman $(n=20)$

\begin{tabular}{llcc} 
& & \multicolumn{2}{c}{ Istri } \\
\hline Umur & $\begin{array}{c}\text { Jumlah } \\
(\mathrm{n})\end{array}$ & $\begin{array}{c}\text { Perse } \\
\text { ntase } \\
(\%)\end{array}$ \\
\hline & $\begin{array}{l}17-25 \\
\text { tahun }\end{array}$ & 10 & 50,0 \\
\hline & $\begin{array}{l}26-35 \\
\text { tahun }\end{array}$ & 10 & 50,0 \\
\hline & $\begin{array}{l}36-45 \\
\text { tahun }\end{array}$ & - & - \\
\hline $\begin{array}{l}\text { Pendidika } \\
\mathrm{n}\end{array}$ & SD & - & - \\
\hline & SMP & 4 & 20,0 \\
\hline & SMA & 13 & 65,0 \\
\hline & D3 & 1 & 5,0 \\
\hline & S1 & 2 & 10,0 \\
\hline Pekerjaan & Swasta & 5 & 25,0 \\
\hline & & & \\
\hline
\end{tabular}




\begin{tabular}{lcc}
\hline Wiraswast & 4 & $\begin{array}{c}20, \\
\text { a }\end{array}$ \\
\hline Buruh & 1 & 5,0 \\
\hline Tidak & 10 & $\begin{array}{c}50, \\
\text { Bekerja }\end{array}$ \\
\hline
\end{tabular}

Sumber: Data primer 2015

Berdasarkan Tabel 1 dapat diketahui bahwa terdapat dua karakteristik responden yaitu karakteristik suami dan istri. Di mana didapatkan hasil, sebagian besar istri berumur 17-35 tahun sebanyak 20 responden. Berdasarkan tingkat pendidikan mayoritas suami tamat SMA sebanyak 13 responden (65,0\%). Istri sebagian besar tidak bekerja, ada 10 responden $(50,0 \%)$.

\section{Gambaran Tingkat Dukungan Suami}

Gambaran tingkat dukungan suami saat persalinan pada ibu primigravida di Puskesmas Mlati II Kabupaten Sleman disajikan pada Tabel 2

\section{Tabel 2 Tingkat Dukungan Suami} Saat Persalinan Pada Ibu

Primigravida di Puskesmas Mlati II Kabupaten Sleman $(\mathbf{n = 2 0 )}$

\begin{tabular}{|c|c|c|c|}
\hline \multicolumn{2}{|c|}{ Variabel } & $\begin{array}{c}\text { Jumlah } \\
\text { (n) }\end{array}$ & $\begin{array}{c}\text { Persentas } \\
\text { e }(\%)\end{array}$ \\
\hline \multirow[t]{3}{*}{$\begin{array}{l}\text { Dukunga } \\
\text { n suami }\end{array}$} & $\begin{array}{l}\text { Kuran } \\
\mathrm{g}\end{array}$ & 1 & 5,0 \\
\hline & $\begin{array}{l}\text { Cuku } \\
\text { p }\end{array}$ & 4 & 20,0 \\
\hline & Baik & 15 & 75,0 \\
\hline Jumlah & Total & 20 & 100,0 \\
\hline
\end{tabular}

Sumber: Data primer 2015

Berdasarkan Tabel 2 diketahui bahwa dari 20 responden, memberikan dukungan baik sebanyak 15 responden (75,0\%), sebanyak 4 responden $(20,0 \%)$ kategori cukup, dan 1 responden $(5,0 \%)$ kategori kurang.

\section{Gambaran Tingkat Kecemasan Saat Persalinan Pada Ibu PrimigravidaDi Puskesmas Mlati II Kabupaten Sleman}

Gambaran tingkat kecemasan saat persalinan pada ibu primigravida di Puskesmas Mlati II Kabupaten Sleman disajikan pada Tabel 3

Tabel 3 Tingkat Kecemasan Saat Persalinan Pada Ibu Primigravida Di Puskesmas Mlati II Kabupaten Sleman $(n=20)$

\begin{tabular}{|c|c|c|c|}
\hline \multicolumn{2}{|c|}{ Variabel } & $\begin{array}{c}\text { Jumla } \\
\mathrm{h}(\mathrm{n})\end{array}$ & $\begin{array}{c}\text { Persenta } \\
\text { se }(\%)\end{array}$ \\
\hline \multirow[t]{3}{*}{$\begin{array}{l}\text { Kecemas } \\
\text { an }\end{array}$} & $\begin{array}{l}\text { Ringa } \\
\mathrm{n}\end{array}$ & 10 & 50,0 \\
\hline & & 7 & 35,0 \\
\hline & $\begin{array}{l}\text { Berat } \\
\text { Panik }\end{array}$ & $\begin{array}{l}2 \\
1\end{array}$ & $\begin{array}{c}10,0 \\
5,0\end{array}$ \\
\hline Jumlah & & 20 & 100,0 \\
\hline
\end{tabular}

Berdasarkan Tabel 3 diketahui bahwa dari 20 responden yang mengalami kecemasan ringan sebanyak 10 responden (50,0\%), kecemasan sedang 7 responden $(35,0 \%)$, mengalami kecemasan berat 2 responden $(10,0 \%)$, dan kecemasan kategori panik 1 responden $(5,0 \%)$.

\section{Hubungan Dukungan Suami Dengan Kecemasan Saat Persalinan Pada Ibu Primigravida Di Puskesmas Mlati II Kabupaten Sleman}

Hubungan antara dukungan suami dengan kecemasan saat persalinan pada ibu primigravida di Puskesmas Mlati II Kabupaten Sleman menggunakan uji Korelasi Spearman yang disajikan pada Tabel 4 
Tabel 4 Hubungan Dukungan Suami Dengan Kecemasan Saat Persalinan Pada Ibu Primigravida Di Puskesmas Mlati II Kabupaten Sleman

\begin{tabular}{|c|c|c|c|c|c|c|c|}
\hline \multirow{2}{*}{$\begin{array}{l}\text { Duku } \\
\text { ngan } \\
\text { suami }\end{array}$} & \multicolumn{5}{|c|}{ Tingkat kecemasan } & \multirow[b]{2}{*}{$r$} & \multirow[b]{2}{*}{$p$} \\
\hline & $\begin{array}{c}\text { Ring } \\
\text { an }\end{array}$ & $\begin{array}{c}\text { Seda } \\
\text { ng }\end{array}$ & $\begin{array}{c}\text { Bera } \\
t\end{array}$ & $\begin{array}{c}\text { Pani } \\
\text { k }\end{array}$ & $\begin{array}{c}\text { Tota } \\
\text { I }\end{array}$ & & \\
\hline Kuran & 0 & 0 & 0 & 1 & 1 & 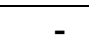 & 0,0 \\
\hline$g$ & $\begin{array}{c}(0,0 \\
\%)\end{array}$ & $\begin{array}{c}(0,0 \\
\%)\end{array}$ & $\begin{array}{l}(0,0 \\
\%)\end{array}$ & $\begin{array}{c}(100 \\
\%)\end{array}$ & $\begin{array}{c}(100 \\
\%)\end{array}$ & $\begin{array}{r}0,6 \\
32\end{array}$ & 03 \\
\hline $\begin{array}{l}\text { Cuku } \\
\text { p }\end{array}$ & $\begin{array}{c}0 \\
(0,0 \\
\%)\end{array}$ & $\begin{array}{c}3 \\
(75,0 \\
\%)\end{array}$ & $\begin{array}{c}1 \\
(25 \\
\%)\end{array}$ & $\begin{array}{c}0 \\
(0,0 \\
\%)\end{array}$ & $\begin{array}{c}4 \\
(100 \\
\%)\end{array}$ & & \\
\hline Baik & $\begin{array}{c}10 \\
(66, \\
\%)\end{array}$ & $\begin{array}{c}4 \\
(26,7 \\
\%)\end{array}$ & $\begin{array}{c}1 \\
(6,7 \\
\%)\end{array}$ & $\begin{array}{c}0 \\
(0,0 \\
\%)\end{array}$ & $\begin{array}{c}15 \\
(100 \\
\%)\end{array}$ & & \\
\hline
\end{tabular}

(20,0\%) kategori cukup, dan 1 responden $(5,0 \%)$ kategori kurang. Dukungan suami dalam proses persalinan merupakan sumber kekuatan bagi ibu yang tidak dapat diberikan oleh tenaga kesehatan. ${ }^{(8)} \mathrm{Hal}$ ini menunjukkan bahwa dukungan suami pada ibu primigravida di Puskesmas Mlati II Kabupaten Sleman sangat baik. Hasil penelitian ini sejalan dengan penelitian yang dilakukan oleh Elisa, kelompok yang didampingi oleh suami sebanyak 23 responden $(50,0 \%)$ dan untuk kelompok yang tidak didampingi oleh suami sebanyak 23 responden $(50,0 \%)$. ${ }^{(9)}$

Suami memberikan dukungan baik secara fisik maupun secara moril yang meliputi: dukungan fisik seperti memberikan minum atau makan kepada istri selama proses bersalin, memegang tangan istri, dan suami mengusap keringat istri. Sedangkan dukungan moril berupa menenangkan istri saat rasa sakit kontraksi timbul, memberikan dorongan semangat mengedan saat kontraksi, dan memanggil istri dengan sapaan yang lembut. Kehadiran suami untuk memberikan dukungan adalah hal yang sangat penting bagi istri selama menjalani proses persalinan, kehadiran suami yang mendampingi ibu saat bersalin banyak memberikan dampak positif bagi ibu khususnya dalam menurunkan kecemasan sehingga mendukung kelancaran proses persalinan.

1. Tingkat Kecemasan Saat Persalinan Pada Ibu Primigravida Di Puskesmas Mlati II Kabupaten Sleman 
Dari 20 ibu sebanyak 10 responden $(50,0 \%)$ mengalami kecemasan ringan, sebanyak tujuh responden (35,0\%) mengalami kecemasan sedang, sebanyak dua responden $(10,0 \%)$ mengalami kecemasan berat, dan satu responden $(5,0 \%)$ mengalami kecemasan kategori panik. Berdasarkan hasil penelitian ibu primigravida di Puskesmas Mlati II Kabupaten Sleman mengalami cemas sedang sebanyak $35,0 \%$ disertai tanda-tanda percaya diri dalam menjalani persalinan, merasa tegang selama proses persalinan, percaya bahwa janin sehat, dan merasa yakin bahwa janin sehat selama proses persalinan. Sedangkan sebanyak 10,0\% mengalami cemas berat dengan tanda-tanda selama proses persalinan merasa tangan gemetar, mudah marah, dan kehilangan selera makan. Sebanyak 5,0\% mengalami kecemasan panik dengan tanda-tanda selama proses pesalinan merasa takut, merasa sakit luar biasa sehingga timbul keinginan persalinan segera diakhiri dengan tindakan operasi atau vakum dan merasa persalinan merupakan beban yang berat dan tidak sanggup menghadapinya.

Berdasarkan hasil penelitian terdapat dua responden mengalami kecemasan dalam kategori cemas berat hal tersebut terjadi dikarenakan selama kehamilan ibu kurang teratur dalam melakukan kunjungan ANC dikarenakan tidak mendapatkan izin di tempat bekerja sehingga ibu hanya melakukan dua kali kunjungan saja, ibu kurang dalam memperoleh informasi terutama tentang pentingnya melakukan ANC dan proses dalam menghadapi persalinan sehingga ibu mengalami kecemasan dalam kategori cemas berat.

2. Hubungan Antara Dukungan Suami Dengan Kecemasan Saat Persalinan Pada Ibu Primigravida Di Puskesmas Mlati II Kabupaten Sleman

Berdasarkan Tabel 4 diketahui bahwa istri yang mendapat dukungan suami kategori kurang mengalami kecemasan dalam kategori panik ada satu responden $(100,0 \%)$, istri yang mendapatkan dukungan suami kategori cukup sebagian besar mengalami tingkat kecemasan sedang ada tiga responden $(75,0 \%)$, dan yang mendapat dukungan suami kategori baik mengalami kecemasan ringan sebanyak 10 responden $(66,7 \%)$. Setelah dilakukan uji Korelasi Spearman diperoleh nilai $p=0,003$ $(p<0,05)$ yang berarti terdapat hubungan yang bermakna antara dukungan suami dengan kecemasan saat persalinan pada ibu primigravida. Hal ini menunjukkan kehadiran suami, ibu primigravida di Puskesmas Mlati II Kabupaten Sleman sangat mambantu ibu dalam proses persalinan sehingga ibu benar-benar percaya diri bisa menjalani persalinan ini. Hasil penelitian ini juga sejalan dengan penelitian Elisa, menunjukkan bahwa terdapat Hubungan Pendampingan Suami Dengan Tingkat Kecemasan lbu 
Primigravida Dalam Menghadapi Proses

Persalinan dengan nilai $(p=0,007)$.

Keeratan hubungan antara kedua variabel dalam kategori kuat dengan hasil $r=-0,632$ berada pada interval 0,6000,799 . Koefisien korelasi ( $r$ ) bertanda negatif berati bahwa semakin baik dukungan suami dapat menurunkan tingkat kecemasan saat persalinan pada ibu primigravida dalam menghadapi persalinan. Hasil penelitian ini sejalan dengan penelitian yang dilakukan oleh Elisa, yaitu dari nilai odds ratio (OR) dapat disimpulkan bahwa tanpa ada pendampingan suami saat proses persalinan mempunyai peluang 6,750 kali untuk terjadi kecemasan dibandingkan ibu yang menghadapi proses persalinan dengan pendampingan.

\section{KESIMPULAN DAN SARAN}

Kesimpulan yang dapat diperoleh dari penelitian ini yaitu: terdapat hubungan yang signifikan antara dukungan suami dengan kecemasan saat persalinan pada ibu primigravida di Puskesmas Mlati II Kabupaten Sleman, yaitu sebagian besar dukungan suami saat persalinan pada ibu primigravida di Puskesmas Mlati II Kabupaten Sleman dalam kategori baik sebanyak 15 responden $(75,0 \%)$. Sebagain besar tingkat kecemasan saat persalinan pada ibu primigravida di Puskesmas Mlati II Kabupaten Sleman dalam kategori ringan sebanyak 10 responden $(50,0 \%)$.
Terdapat hubungan yang bermakna antara dukungan suami dengan kecemasan saat persalinan pada ibu primigravida di Puskesmas Mlati II Kabupaten Sleman $p=0,003(p<0,05)$. Keeratan hubungan antara dukungan suami dengan kecemasan saat persalinan pada ibu primigravida di Puskesmas Mlati II Kabupaten Sleman dalam kategori kuat $r=-0,632(0,600-0,799)$.

Berdasarkan hasil penelitian tersebut, maka peneliti memberikan saran-saran yaitu, masyarakat diharapkan dapat menghadirkan suami untuk memberi dukungan pada ibu yang akan melahirkan agar persalinannya berjalan dengan baik dan lancar. Perawat atau Tenaga Kesehatan diharapkan dapat melakukan upaya untuk peningkatan mutu kualitas pelayanan kebidanan dengan menghadirkan suami pada saat ibu bersalin sebagai wujud pemberian dukungan suami selama persalinan. Penelitian berikutnya diharapkan dapat menambah variabel penelitian dan sebaiknya dilakukan uji coba lembar observasi pada tempat penelitian yang lain

\section{KEPUSTAKAAN}

1. WHO. Pelayanan Kesehatan Maternal. Jakarta: Media Aesclapius Press. 2006.

2. Hasuki. Buku Saku Perawatan Kesehatan Ibu dan Anak. Jakarta: EGC. 2010.

3. Kemkes RI. Upaya Percepatan Penurunan Angka Kematian Ibu. Jakarta: Bakti Husada. 2011.

4. Sumarah, et al. Perawatan lbu Bersalin. Yogyakarta: Fitramiya. 2008. 
5. Sari \& Rimandini. Asuhan Kebidanan Persalinan. Jakarta: Trans Info Media. 2014.

6. Hurlock. Psikologi Perkembangan Suatu Pendekatan Sepanjang Rentang Kehidupan. Edisi Keenam. Jakarta: Erlangga. 2001.

7. Nugroho. Besar Sampel Dalam Penelitian Kesehatan.Yogyakarta: Books. 2010.

8. Marmi. Intranatal Care Asuhan Kebidanan Pada Persalinan. Yogyakarta: Pustaka Pelajar. 2012.

9. Elisa. Hubungan Pendampingan Suami Dengan Tingkat Kecemasan Ibu Primigravida Dalam Menghadapi Proses Persalinan di BPS Wilayah Kerja Puskesmas Banjarmasin. Program Studi IImu Keperawatan STIKES Telogorejo Semarang. 2013. 